\title{
A conformational change of the domain IV S6 segment of the voltage-gated sodium channel during inactivation
}

\author{
Vaibhavkumar S Gawali, René Cervenka, Péter Lukács, Xaver Koenig, Lena Rubi, Ágnes K Mike, Karlheinz Hiber, \\ Hannes Todt
}

From 18th Scientific Symposium of the Austrian Pharmacological Society (APHAR). Joint meeting with the Croatian, Serbian and Slovenian Pharmacological Societies.

Graz, Austria. 20-21 September 2012

\section{Background}

In voltage-gated $\mathrm{Na}^{+}$channels the $\mathrm{S} 6$ transmembrane segment of domain IV (DIV-S6) is part of the lining of the inner part of the pore. It is of pivotal importance for inactivation gating. We recently showed that amino acid I1581 of DIV-S6 ( $\mathrm{rNa}_{V} 1.4$ amino acid numbering) is extraordinarily sensitive to both local and distal mutations suggesting a unique role in coupling of voltagesensor movements to conformational changes in the pore. To date the only structural information relevant to voltage-gated $\mathrm{Na}^{+}$channels can be derived from the recently crystallized bacterial channel $\mathrm{Na}_{\mathrm{V}} \mathrm{Ab}$. In this structure the amino acid homologous to I1581 faces the lipid phase and is in close spacial relationship to the voltage-sensing apparatus. If this arrangement holds true for the eukaryotic $\mathrm{Na}^{+}$channel then site 1581 should not be exposed to bulk solution.

\section{Methods}

The following methods were used: site-directed mutagenesis of amino acids in the S6 segment of domain IV of the $\mathrm{rNa}_{\mathrm{V}} 1.4$ channel; heterologous expression of the constructs in tsA 201 cells and Xenopus laevis oocytes; exploration of the kinetic effects of the mutations and gating sensitivity of the amino acid residue in the S6 segment of domain IV of the $\mathrm{rNa}_{\mathrm{V}} 1.4$ channel by whole-cell patch clamp and two-electrode voltage clamp technique.

\section{Results}

We tested the hypothesis by replacing I1581 by a titrable histidine. In wild-type channels changing the $\mathrm{pH}$ of the bulk solution from 7.4 to 8.2 had no effect on the voltagedependence of fast inactivation. However, in $11581 \mathrm{H}$ the same change in $\mathrm{pH}$ resulted in a $9.51 \pm 1.98 \mathrm{mV}$ hyperpolarizing shift $(\mathrm{p}<0.05)$ of the voltage-dependence of fast inactivation.

\section{Conclusions}

The data suggest that during inactivation site 1581 is at least partially exposed to the bulk solution and not completely embedded in the lipid phase. The DIV-S6 segment may undergo a conformational change during inactivation, most likely a rotational movement, which allows access of external protons to site 1581 .

\section{Acknowledgements \\ This study was funded by the Austrian Science Fund FWF (grants P210006- B11 and W1232-B11).}

Published: 17 September 2012

doi:10.1186/2050-6511-13-S1-A60

Cite this article as: Gawali et al:: A conformational change of the domain IV S6 segment of the voltage-gated sodium channel during inactivation. BMC Pharmacology and Toxicology 2012 13(Suppl 1):A60.

\footnotetext{
* Correspondence: hannes.todt@meduniwien.ac.at Department of Neurophysiology and Neuropharmacology, Center for Physiology and Pharmacology, Medical University of Vienna, 1090 Vienna, Austria
}

(c) 2012 Gawali et al; licensee BioMed Central Ltd. This is an Open Access article distributed under the terms of the Creative Commons 